\title{
Familial idiopathic granulomatosis: sarcoidosis and Crohn's disease in two Indian families
}

\author{
Pradeep Bambery, Upjeet Kaur, S R Bhusnurmath, J B Dilawari
}

\begin{abstract}
The coexistence of sarcoidosis and Crohn's disease in different members of the same family is rare and only two instances are on record. Two Indian families showing this association have been studied. In one a brother and sister are affected, and in the other seven and possibly eight persons in two generations have been affected. The familial occurrence of both these conditions supports the view that a transmissible agent may be concerned in the genesis of both diseases in genetically susceptible individuals.
\end{abstract}

The familial occurrence of a disease may contribute towards a clearer understanding of its pathogenesis, particularly when the aetiology is uncertain. Sarcoidosis and Crohn's disease are good examples. ${ }^{1}$ These conditions have been considered to be readily distinguishable from each other ${ }^{1}$ but recent research suggests that this may not be so. ${ }^{2}$ Some of the features that were thought to occur in only one condition have now been observed in both. ${ }^{12}$ Sarcoidosis and Crohn's disease $^{3}$ are rare in India but are now being seen with increasing frequency. ${ }^{34}$ They may have been mistaken for tuberculosis in the past. ${ }^{3}$ The coexistence of these two uncommon conditions in the same family has been recorded only twice. ${ }^{56} \mathrm{We}$ describe two Indian families where sarcoidosis and Crohn's disease have affected different members.

\section{Case reports}

FAMILY 1

Patient 1 A 50 year old housewife developed a low grade intermittent pyrexia (37.5$38.5^{\circ} \mathrm{C}$ ), anorexia, and lethargy in 1980 . Physical examination and laboratory tests showed nothing abnormal but the fever persisted. In 1981 she had a documented lower urinary tract infection, which responded to antibiotics. In 1982 she developed erythema nodosum, arthralgia, and severe anterior and posterior uveitis, which responded to corticosteroids but flared up whenever an attempt was made to reduce the dose. Bilateral hilar lymphadenopathy was noted on her chest radiograph and later the same year a cervical gland biopsy showed discrete non-caseating epithelioid cell granulomas with occasional giant cells. As the histological features resembled tuberculosis she was treated with isoniazid, pyrazinamide, and ethambutol for 18 months even though the tissue was negative for acid fast bacilli on stains and in culture. While having this treatment she developed bilateral parotid swelling and a left seventh cranial nerve palsy. A diagnosis of sarcoidosis was considered and a Kveim test gave a positive result. Disease activity continued until 1985 and then subsided. She is currently symptom free and has not received corticosteroids for five years.

Patient 2 The 56 year old brother of patient 1 developed fever, abdominal pain, and an altered bowel habit in 1978. Initial examination showed nothing remarkable but a discrete, firm lump became palpable in the caecal region in 1979. At colonoscopy the caecum was deformed, inflamed, and ulcerated but there was no evidence of malignancy in several biopsy specimens. Suspected of having amoebiasis, he was treated with metronidazole and had some relief. He had severe pain, colic, distension, vomiting, and right lower quadrant tenderness, however, in 1980, and underwent an emergency laparotomy elsewhere. The terminal ileum was found to be thickened, rigid, indurated, and encased in mesenteric fat. The paracolic region had several pockets of pus, which were drained. No resection was carried out. He was advised to take isoniazid, ethambutol, and thiacetazone for 18 months. He remained well for a few months but symptoms recurred in 1981, when he had several episodes of subacute intestinal obstruction with fever. Repeat colonoscopy showed aphthous ulcers in the caecum and several biopsy specimens showed granulomatous colitis consistent with Crohn's disease. No further treatment was prescribed. Since then he has been well except for mild colic on several occasions.

\section{FAMILY 2}

This is a large family with eight affected members in two generations (figure). There has been no consanguinity and the origin of the family is entirely north Indian. Only one member of the family at present resides in India (patient 8) and the details of her illness are given below. As the others have not been examined by us personally their clinical problems are summarised.

Patient 1 Died aged 45 years from a chronic respiratory illness and cor pulmonale. No histological specimens were obtained.

Patient 2 Died aged 60 years of an illness very similar to that of his brother (patient 1 ). In addition he had dermal plaques and nodules, from which a tissue diagnosis of 
Family tree of the second family, showing six members with sarcoidosis $(1,2,3,4,7$, and 8) and two with Crohn's disease (5 and 6). The parents died of cardiac causes and the son of patient 2 had a brain tumour.

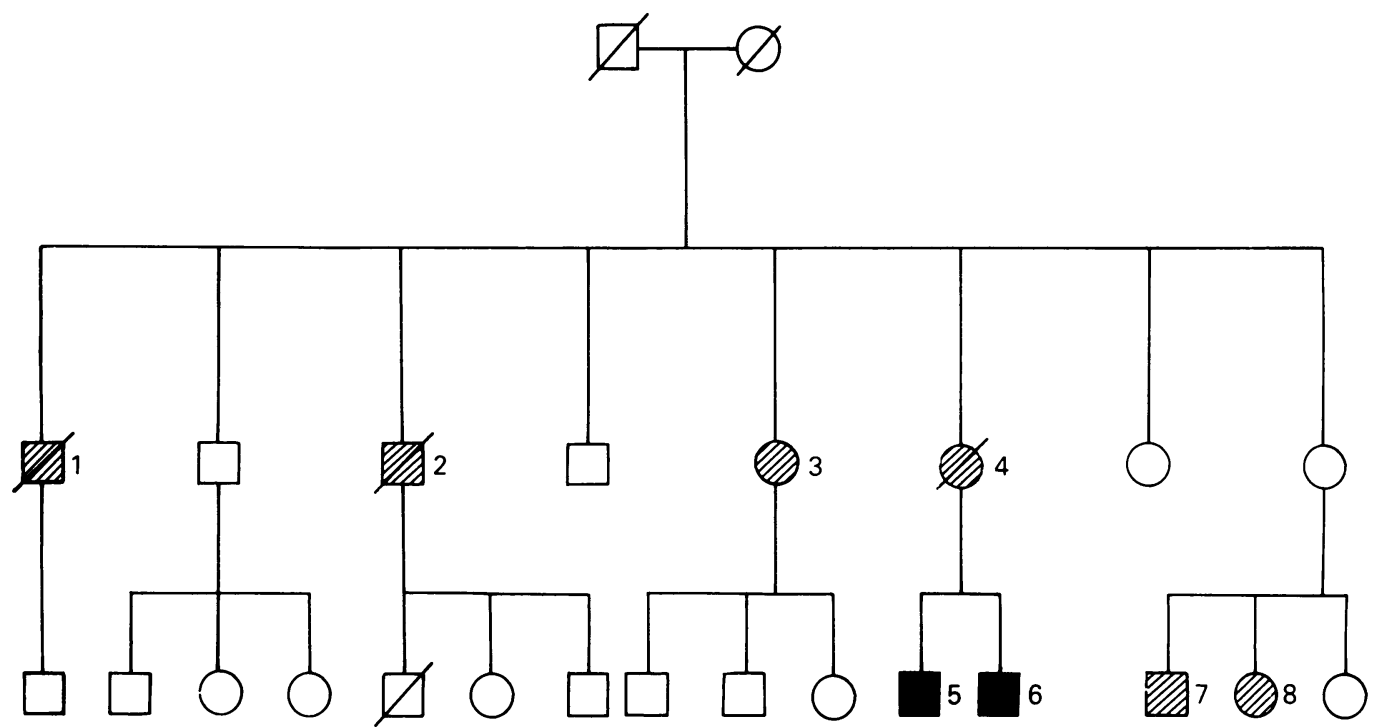

sarcoidosis was made before he died.

Patient 3 is living and being treated for dermal, pulmonary, and cardiac sarcoidosis in the United States. The diagnosis has been confirmed histologically. She is 72 years old.

Patient 4 Died aged 70 years. She had had histologically confirmed sarcoidosis of the skin, eyes, and lungs for several years.

Patient 5 is aged 43 and resident in England. $\mathrm{He}$ has a permanent ileostomy for severe Crohn's disease.

Patient 6 is the 40 year old brother of patient 5, and is also resident in England. He also has an ileostomy for Crohn's disease. In addition, he had nodular skin lesions on the legs.

Patient 7 is 44 years old and living in Canada. $\mathrm{He}$ has had ill health with fever, lymphadenopathy, and cough, but does not have histologically confirmed sarcoidosis. The tuberculin test response was negative.

Patient 8, a 40 year old housewife, developed thickening, redness, and dryness of the skin over the malar region in 1986. The lesion was mildly photosensitive. She also had cervical lymphadenopathy. Skin biopsy showed discrete epithelioid cell granulomas with occasional giant cells, no caseation, and no acid fast bacilli. Her chest radiograph and spirometric indices were normal, but she had hypercalcaemia and hypercalciuria. She responded well to corticosteroids and attempts to taper the dose for the first three years were followed by a relapse. For the last year the disease appears to be quiescent, though in 1989 she passed a urinary calculus. At present she is taking a small, alternate day dose of prednisolone.

\section{Discussion}

Although familial sarcoidosis is well described the mode of inheritance is not clear. ${ }^{17-9}$ HLA studies in different ethnic populations have shown variable associations. ${ }^{10}$ The $\mathrm{B} 8 / \mathrm{CW} 7 /$ DR3 haplotype has been found to be related to acute articular, dermal, and ocular sarcoidosis, with a good prognosis in English patients. ${ }^{11}$ Familial aggregates of $\mathrm{A} 2 / \mathrm{B} 7 / \mathrm{CW} 7 /$
DR2/DR7 and A2/B5/CW7/DR5 have been reported. ${ }^{12}{ }^{13}$ Family studies in inflammatory bowel disease have clearly established that a familial incidence is far greater than would be expected by chance. ${ }^{14}$

Sarcoidosis and Crohn's disease were believed to be easily distinguishable granulomatous conditions of unknown aetiology. Whereas the former is usually widely disseminated, the latter is considered to be limited to the bowel predominantly. Bowel lesions in sarcoidosis are very infrequent even at necropsy. ${ }^{1}$ Evidence, however, suggests that the two conditions may have more features in common than has been recognised, despite the fact that the two pioneers, Crohn and Siltzbach, were both working at Mt Sinai Hospital in New York. The extraintestinal manifestations of Crohn's disease show some similarity to some of the dermal, articular, and ocular presentations of sarcoidosis. Lymphocytic alveolitis, long considered a hallmark of sarcoidosis, has been shown to occur in Crohn's disease. $^{2}$ There have been well documented reports on patients with both diseases ${ }^{15-17}$ and on at least two families ${ }^{56}$ in which the two conditions have coexisted.

The interplay of the genetic makeup of the individual with the environment in the development of disease has been strongly supported by several studies. Acute sarcoidosis has been documented in close relatives who have lived together, and this has been used as evidence for the existence of a transmissible agent responsible for the disease. ${ }^{718}$ There has been a great resurgence of interest in the idea that mycobacteria may be responsible for both sarcoidosis $^{1920}$ and Crohn's disease. ${ }^{2122}$ This has been based on the detection of protoplastic forms of mycobacteria in tissue in both conditions. ${ }^{2022}$ Possibly the two conditions are manifestations of the same disease, which occurs in susceptible persons and is modulated by a genetically determined abnormal immunological response to mycobacteria. The seemingly different clinical features could be explained by different routes of entry of the antigenic stimulus-inhalation for sarcoidosis 
and ingestion for Crohn's disease. The reported familial clustering of these conditions supports this contention.

We are grateful to Professor A M Denman, Northwick Park Hospital and Clinical Research Centre, Harrow, UK, for
details of the treatment of the patient who has been under his details of the treatment of the patient who has been un
care; and to Ms Kuldeep Virdi for secretarial assistance.

1 James DG, Jones Williams W. Sarcoidosis and other granulomatous disorders. Philadelphia: Saunders, 1985:144-62. (Major problems in internal medicine vol 24.)

2 Voisin C, Wallaert B, Dugas M, Bonniere P, Cortot A Martinot JB, et al. Biological characteristics and significance of subclinical inflammatory alveolitis in extrathoracic granulomatous disorders. In: Grassi C, Rizzato G, Pozzi E, eds. Sarcoidosis and other granulomatous disorders. Amsterdam: Elsevier, 1988:35-49.

3 Bambery P, Behera D, Gupta A, et al. Sarcoidosis in North India: clinical profile of $\mathbf{4 0}$ patients. Sarcoidosis 1987; 4:155-8.

4 Gupta SK. Sarcoidosis: Clinical aspects. In: Grassi C, Rizzato G, Pozzi E, eds. Sarcoidosis and other granulomatous disorders. Amsterdam: Elsevier, 1988:397-406.

5 Willoughby JMT, Mitchell DN, Wilson JD. Sarcoidosis and Crohn's disease in siblings. Am Rev Respir Dis 1971; 104:249-53.

6 Gronhagen-Riska C, Fyhrquist F, Hortling L, Koskimies S. Familial occurrence of sarcoidosis and Crohn's disease. Lancet 1983; : 1287-8.

7 Brennan NJ, Crean P, Long JP, FitzGerald MX. High prevalence of familial sarcoidosis in an Irish population. Thorax 1984;39:14-8.

8 British Thoracic and Tuberculosis Association. Familial associations in sarcoidosis. Tubercle 1973;54:87-98.

9 Headings VE, Weston D, Young RC, Hackney RL. Familial sarcoidosis with multiple occurrences in eleven families: a possible mechanism of inheritance. Ann NY Acad Sci 1976;278:377-85.

10 Mehra NK. Bovornkitti S. HLA and sarcoidosis. Sarcoidosis 1989;5:87-9.

11 Gardner J, Kennedy HG, Hamblin A, Jones E. HLA associations in sarcoidosis: a study of two ethnic groups. Thorax 1984;39:19-22.

12 Andrews JL, Campbell JC, Rocklin RE, Garovoy MR. Familial sarcoidosis: clinical, immunologic and genetic features of an unusual variant. In: Grassi C, Rizzato G, Pozzi E, eds. Sarcoidosis and other granulomatous disorders. Amsterdam: Elsevier, 1988:291-6.

13 Luisetti M, Cremaschi P, Rizzo S,. Martinetti M, Belvedere M. Report of one case of familial sarcoidosis. Sarcoidosis 1988;5:90-2.

14 Lewkonia RM, McConnell RB. Familial inflammatory bowel disease. Heredity or environment? Gut 1976;17:235-43.

15 Padilla AJ, Sparberg M. Regional enteritis and sarcoidosis in one patient. Gastroenterology 1972;63:153-60.

16 Oakley JR, Lawrence DAS, Fiddian RV. Sarcoidosis associated with Crohn's disease of ileum, mouth and oesophagus. J R Soc Med 1983;76:1068-71.

17 Scadding JG, Mitchell DN. Sarcoidosis. 2nd ed. London: Chapman and Hall, 1985:374.

18 Sharma OP, Johnson CS, Balchum OJ. Familial sarcoidosis, report of four siblings with acute sarcoidosis. Am Rev Respir Dis 1971;104:255-7.

19 Hanngren A, Odham G, Eklund A, Hoffner S, Stjernberg N, Westerdahl G. Tuberculostearic acid in lymphnodes from patients with sarcoidosis. Sarcoidosis 1987;4:101-4.

20 Graham DY, Markesich DC, Kalter DC, Yoshimura HH. Isolation of cell wall defective acid fast bacteria from skin lesions in patients with sarcoidosis. In: Grassi C, Rizzato G, Pozzi E, eds. Sarcoidosis and other granulomatous disorders. Amsterdam: Elsevier, 1988:161-4.

21 Mitchell DN, Rees RJW, Goswami KKA. Transmissible agents from human sarcoid and Crohn's disease tissues. Lancet 1976;ii:761-5.

22 Chiodini RJ, van Kriuningen HJ, Thayer WR, Merkal RS, Coutu JA. Possible role of mycobacteria in inflammatory bowel disease. Dig Dis Sci 1984;29:1073-9. 